\title{
Osteophytes in the osteoarthritic hand: their incidence, size, distribution, and progression
}

Department of Anatomy, United Medical and Dental Schools of Guy's and St Thomas's Hospitals, Guy's Campus, London SE1 9RT I C Buckland-Wright J A Lynch

Department of Rheumatology, United Medical and Dental Schools of Guy's and St Thomas's Hospitals, Guy's Campus, London SE1 9RT D G Macfarlane

Correspondence to: Dr Buckland-Wright. Accepted for publication 1 August 1990

\begin{abstract}
Quantitative microfocal radiographic assessment of osteophytes in osteoarthritic hands showed that their number and area were greatest at joint margins, in the dominant hand, in the second and third compared with fourth and fifth phalanges, in the third phalanx, and in the second distal interphalangeal joint respectively. These sites correspond with those for the largest forces exerted in the hand: the dominant side, the finger tripod used in the precision grip, power grip, and pulp-pinch respectively. The greater osteophytosis on the trapezium of the nondominant first carpometacarpal joint was probably related to forces exerted during power grip. Osteophytes increased significantly in number and area during the 18 month study period.
\end{abstract}

Osteophytes are the classic radiographic and pathological hallmark of osteoarthritis, but their role as the sole diagnostic marker of osteoarthritis is questioned ${ }^{\mathbf{l}}$ as they also correlate with age. ${ }^{2-4}$ The presence of osteophytes in most experimentally induced models of osteoarthritis, in many species of animals, however, supports the contention that osteophyte formation is a component of the osteoarthritic degenerative process. $^{5}$ In patients with osteoarthritis osteophyte size has been reported to increase with progressive structural disorganisation of their joints. ${ }^{46}$ In osteoarthritis of the hand osteophytes are characteristically seen in the distal and proximal interphalangeal (DIP, PIP) joints. The incidence of osteophytes in these joints has been explained in terms of pinch $v$ grasp actions of the hand. ${ }^{7}$ Investigations have found that textile workers employed for at least 20 years in pinch operations were more prone to DIP joint degeneration than winders, whose actions and osteophyte formation affected the wrist. $^{89}$ It was suggested that the mechanical hypothesis is not always consistent as the first carpometacarpal (CMC) joints of the nondominant hand were more affected than those in the dominant hand. ${ }^{9-11}$

This study undertook a detailed assessment of the distribution of osteophyte formation using microfocal radiography. The results were compared with reports on the pattern of force distribution in the hand. The advantages of high magnification and resolution offered by microfocal radiography ${ }^{12}$ provide not only detail of $x$ ray features approximating to histology ${ }^{13}$ but also accurate quantitative evaluation $^{14}$ of the incidence, size, and distribution of osteophytes at the marginal and capsular sites of each joint in wrists and hands. Progression in the number and area of osteophytes was assessed and their distribution in the wrist and hand with time was studied.

\section{Patients and methods}

Forty five patients were recruited, of whom 32 (three male, 29 female; mean age at first visit 62 (SD 10) years; mean disease duration 11.6 (SD 10) years) completed the full 18 months of the study. All had evidence of two of the three following features in the hands on conventional radiography: subchondral sclerosis, joint space narrowing, and osteophytes. Sixteen patients had interphalangeal nodes on entry, defined as one visible swelling on one joint plus three or more palpable swellings on other hand joints. By the end of the study 25 of the 32 patients had nodal osteoarthritis of the hands. All were carefully examined to exclude other forms of arthritis and all were seronegative for rheumatoid factor and had a normal erythrocyte sedimentation rate. They were allowed to continue taking their normal drugs. Patients were $x$ rayed on entry and every six months for 18 months.

Stereopair macroradiographs $(\times 5)$ were prepared of the right and left wrists and hands of each patient. The hand was placed in a stereotactic unit positioned close to the source and displaced by $6 \mathrm{~mm}$ between each $x$ ray exposure. ${ }^{13}$ The details of this procedure and its accuracy are described elsewhere. ${ }^{14-17}$ The stereopair macroradiographs thus obtained were examined under a large format stereoscope (Ross Instruments, Salisbury, UK) for three dimensional evaluation of the joint structures. $^{1315}$ The right hand, back illuminated carriage of the stereoscope comprised a digitiser tablet linked to an MOP-videoplan (Carl Zeiss, Hertfordshire, UK). A cross wire cursor was used to outline the osteophytes in the macroradiograph overyling the digitiser. A detailed description of the method of measurement and its accuracy in recording $x$ ray features is reported elsewhere. ${ }^{14}$

In the wrist the sites of osteophyte development occurred adjacent to the insertion of the capsule and interosseous ligaments. In the metacarpophalangeal (MCP), PIP, and DIP joints the bones were subdivided on the basis of osteophytes occurring at the juxta-articular margin or pericapsular insertion on both the medial and lateral surfaces of the bones in digits 2-5 (fig 1). From the macroradiographs data on the number and area in square millimetres of osteophytes at each of the sites in both the right 


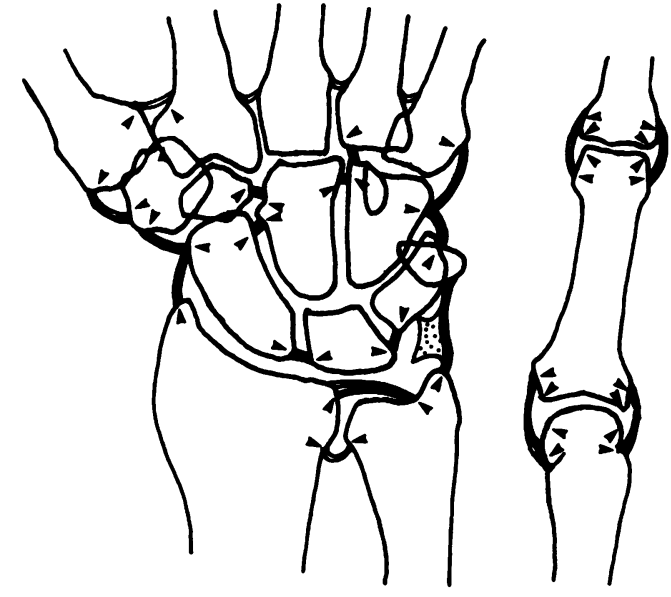

Figure 1 Diagram of the bones of the wrist, metacarpophalangeal, and proximal interphalangeal joints, illustrating the sites at which measurements of osteophyte number and area were carried out. For clarity the arrows indicating the marginal sites in the wrist have been omitted.

and left hands of all patients were recorded separately for the radiographs obtained on the four visits. The data initially recorded on the MOP-videoplan were transferred to an IBM PC/AT microcomputer. A standard format was used in this file for each patient/hand/visit record, enabling comparison of data both within and between patients. The analysis was carried out with the SPSS/PC + statistics package ${ }^{18}$ and some specially written Fortran programs.

The Wilcoxon test was used to compare the difference in number and area of osteophytes in the hand between the groups of joints (DIP, PIP, and MCP), between the separate phalangeal rays, and between individual joints. Within each joint the same test was applied to determine the difference in the number and area of osteophytes between those at the margin and capsular attachment, between the ulnar and radial sides, and between the proximal and distal sides of the joint. Osteophyte progression during the study was calculated from the change in mean osteophyte number and area at the separate regions as well as for the wrist and hand. The significance of any differences was calculated using the Wilcoxon matched pairs test.

\section{Results}

The first radiograph taken at the start of the study showed that osteophytes were present in

Table 1 Mean (standard deviation) of osteophyte number and area in dominant and non-dominant hands and wrists of patients at start of study. The significance of any difference between the two extremities is indicated by an asterisk

\begin{tabular}{|c|c|c|c|c|}
\hline \multirow[t]{2}{*}{ Foint affected } & \multicolumn{2}{|c|}{ Number of osteophytes } & \multicolumn{2}{|c|}{ Area of osteophytes $\left(\mathrm{mm}^{2}\right)$} \\
\hline & Dominant & Non-dominant & Dominant & Non-dominant \\
\hline $\begin{array}{l}\text { Wrist and hand } \\
\text { Hand only } \\
\text { DIPt } \\
\text { PIPt } \\
\text { MCPt } \\
\text { First CMCt } \\
\text { Wrist }\end{array}$ & $\begin{aligned} & 28.7(11 \cdot 8) \\
& 24.5(11.2) \\
& 11.2(4 \cdot 5) \\
& 9.4(5.8) \\
& 3.9(4.2) \\
& 1.5(1.6) \\
& 1.8(1.7)\end{aligned}$ & $\begin{array}{l}26 \cdot 0(11 \cdot 6) \\
21.9(11 \cdot 1)^{*} \\
10.8(4 \cdot 7) \\
7 \cdot 2(5 \cdot 4)^{* * *} \\
3.9(4 \cdot 0) \\
1.8(1 \cdot 5) \\
2.3(2 \cdot 1)\end{array}$ & $\begin{array}{r}62 \cdot 0(46 \cdot 8) \\
45 \cdot 2(44 \cdot 6) \\
21 \cdot 8(27 \cdot 3) \\
16 \cdot 2(19 \cdot 0) \\
7 \cdot 2(9 \cdot 8) \\
10 \cdot 6(18 \cdot 7) \\
6 \cdot 2(9 \cdot 1)\end{array}$ & $\begin{array}{l}59.4(40.9) \\
33.2(30.9)^{* *} \\
16.6(17.9)^{*} \\
11.0(14.9)^{* *} \\
5.6(7.5) \\
20.1(31.7) \\
6.1(8.5)\end{array}$ \\
\hline
\end{tabular}

Test used: Wilcoxon matched pairs. Significance level set at $p=0.05 .{ }^{*} p<0.03$; ${ }^{* *} p<0.02$ ***p<0.001.

$+D \hat{P}=$ distal interphalangeal; $\quad \mathbf{P I P}=$ proximal interphalangeal; $\quad \mathbf{M C P}=$ metacarpophalangeal; CMC = carpometacarpal. the hand and wrist of all 32 patients. In general, few osteophytes were present in the wrist apart from the first carpometacarpal (CMC) joint where osteophytes were present in $27(84 \%)$ patients. Their mean area was much larger than at any other joint in the wrist or hand, though the mean number of osteophytes was similar to that of individual PIP joints (table 1, fig 2).

The mean number and area of osteophytes in the hand and wrist was greater on the dominant than the non-dominant side (table 1). In particular, their area was significantly greater in the DIP and PIP joints of the dominant hand. In the wrist there was no difference between the extremities apart from those on the bones of the first CMC joint. Here, the mean osteophyte area was larger, but not statistically significant, in the non-dominant hand (table 1). Only at the trapezium of the non-dominant hand was the osteophyte area twice as large (14.4 (SD 27.2) $\left.\mathrm{mm}^{2}\right)$ and significantly different $(\mathrm{p}<0.048)$ from that on the dominant hand.

Comparison of the extent of osteophyte formation in the separate horizontal groups of joints showed that their greater mean number and area occurred in the DIP joints, followed by the PIP and then MCP joints in a ratio for osteophyte area of about 3:2:1 respectively. The difference between the three groups was significant $(p<0.05)$ for both number and area, apart from osteophyte number between the DIP and PIP joints of the dominant hand.

Between the separate phalangeal rays the
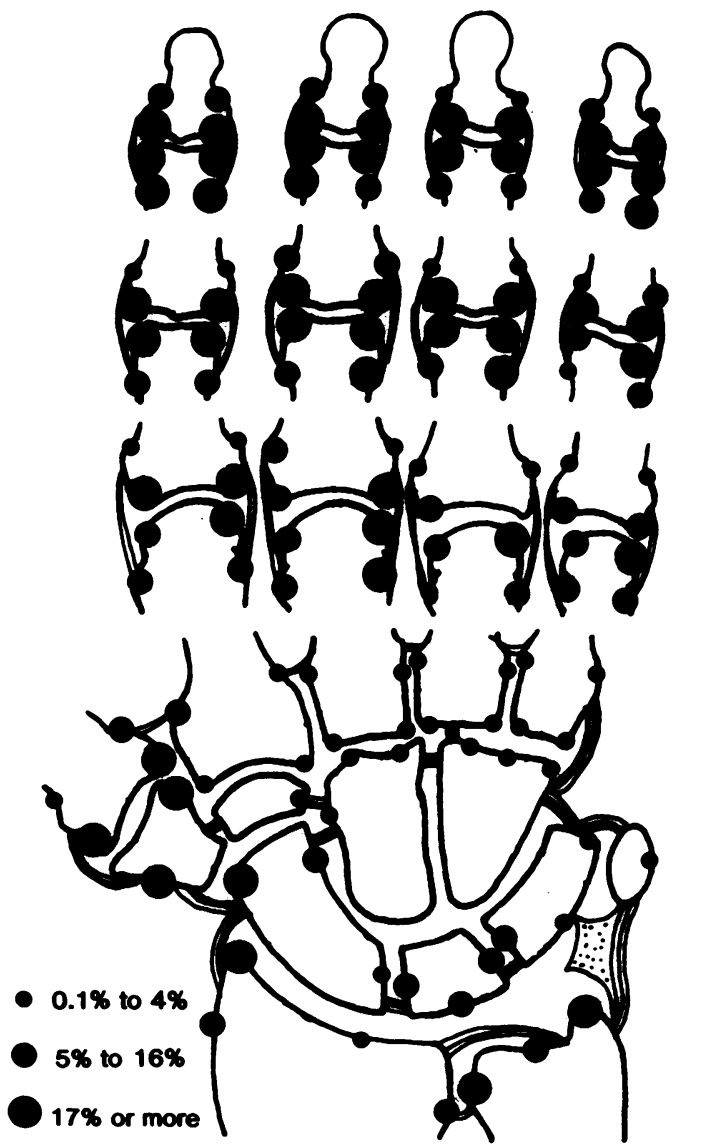

Figure 2 Diagram of the bones of the wrist and hand illustrating the percentage incidence of osteophyte formation at the juxta-articular margins and capsular attachoments of the joints. 
Table 2 Mean (standard deviation) of osteophyte number and area in phalangeal rays and the significance of differences between the rays

\begin{tabular}{|c|c|c|c|c|c|}
\hline \multicolumn{3}{|c|}{ Osteophyte } & \multicolumn{3}{|c|}{ Significance of differences ( $p$ value) } \\
\hline$\overline{R a y}$ & Number & Area $\left(\mathrm{mm}^{2}\right)$ & Rays & Number & Area \\
\hline $\begin{array}{l}\text { 2nd } \\
\text { 3rd } \\
\text { 4th } \\
\text { 5th }\end{array}$ & $\begin{array}{l}6 \cdot 4(3 \cdot 3) \\
7 \cdot 6(4 \cdot 1) \\
4.6(2 \cdot 8) \\
4.6(3 \cdot 3)\end{array}$ & $\begin{array}{rr}12 \cdot 2 & (13 \cdot 1) \\
14 \cdot 2 & (14 \cdot 8) \\
6 \cdot 1 & (8 \cdot 9) \\
5 \cdot 7 & (7 \cdot 9)\end{array}$ & $\begin{array}{l}\text { 2nd-3rd } \\
\text { 2nd-4th } \\
\text { 2nd-5th } \\
\text { 3rd-4th } \\
\text { 3rd-5th } \\
\text { 4th-5th }\end{array}$ & $\begin{array}{l}<0.02 \\
<0.0003 \\
<0.001 \\
<0.0001 \\
<0.0001 \\
\text { NS }\end{array}$ & $\begin{array}{l}\text { NS } \\
<0.0001 \\
<0.001 \\
<0.0001 \\
<0.0001 \\
\text { NS }\end{array}$ \\
\hline
\end{tabular}

Statistical test: Wilcoxon matched pairs. Significance level set at $p=0.05$.

Table 3 Mean (standard deviation) of the number and area of osteophytes at juxta-articular margins $(\mathcal{F}-A)$ and capsular $(C A P)$ attachment in the hand joints. The significance of the difference in osteophyte number and area between those at the two sites are indicated in the space between the two columns

\begin{tabular}{|c|c|c|c|c|c|c|c|c|}
\hline \multirow[t]{2}{*}{ foints } & \multicolumn{2}{|l|}{ Index } & \multicolumn{2}{|l|}{ Middle } & \multicolumn{2}{|l|}{ Ring } & \multicolumn{2}{|l|}{ Litule } \\
\hline & $\mathcal{f}-A$ & $C A P$ & $\mathcal{J}-\boldsymbol{A}$ & $C A P$ & $\mathcal{J}-\boldsymbol{A}$ & $C A P$ & $\boldsymbol{J}-\boldsymbol{A}$ & $C A P$ \\
\hline $\begin{array}{l}\text { Number } \\
\text { DIP } \\
\text { PIP } \\
\text { MCP }\end{array}$ & $\begin{array}{l}2 \cdot 5^{* *} \\
(1 \cdot 3) \\
1 \cdot 8^{* *} \\
(1.5) \\
0.9^{*} \\
(1 \cdot 2)\end{array}$ & $\begin{array}{c}0.7 \\
(0.9) \\
0.3 \\
(0.7) \\
0.3 \\
(0.6)\end{array}$ & $\begin{array}{c}2 \cdot 5^{* *} \\
(1 \cdot 4) \\
2 \cdot 3^{* *} \\
(1 \cdot 6) \\
0 \cdot 8 \\
(1 \cdot 2)\end{array}$ & $\begin{array}{c}0.7 \\
(0.9) \\
0.5 \\
(0.9) \\
0.5 \\
(1.04)\end{array}$ & $\begin{array}{l}2.0^{* *} \\
(1 \cdot 4) \\
1.6^{* *} \\
(1.4) \\
0.4 \dagger \\
(1.0)\end{array}$ & $\begin{array}{c}0.3 \\
(0 \cdot 5) \\
0 \cdot 3 \\
(0 \cdot 7) \\
0 \cdot 2 \\
(0 \cdot 4)\end{array}$ & $\begin{array}{l}1.9 \\
(1.5) \\
1.4^{* *} \\
(1.2) \\
0.5 \mathrm{H} \\
(0.9)\end{array}$ & $\begin{array}{c}0.6 \\
(1.0) \\
0.1 \\
(0.4) \\
0.2 \\
(0.5)\end{array}$ \\
\hline $\begin{array}{l}\text { Area }\left(\mathrm{mm}^{2}\right) \\
\text { DIP } \\
\text { PIP } \\
\text { MCP }\end{array}$ & $\begin{array}{l}5 \cdot 9 * * \\
(8 \cdot 9) \\
2 \cdot 3^{* *} \\
(3 \cdot 5) \\
1 \cdot 2 \mathrm{H} \\
(2 \cdot 2)\end{array}$ & $\begin{array}{c}2.0 \\
(3.5) \\
0.6 \\
(2.4) \\
0.5 \\
(1.5)\end{array}$ & $\begin{array}{l}4 \cdot 3 \mathrm{Ht} \\
(7 \cdot 5) \\
3 \cdot 9 * * \\
(5 \cdot 7) \\
1 \cdot 3 \\
(2 \cdot 7)\end{array}$ & $\begin{array}{c}2 \cdot 1 \\
(4 \cdot 1) \\
0 \cdot 9 \\
(2 \cdot 1) \\
1 \cdot 3 \\
(3 \cdot 04)\end{array}$ & $\begin{array}{c}1 \cdot 8^{* *} \\
(3 \cdot 3) \\
1 \cdot 8^{*} \\
(3 \cdot 4) \\
0 \cdot 6 \\
(1 \cdot 6)\end{array}$ & $\begin{array}{c}0.5 \\
(1.0) \\
1.3 \\
(5.7) \\
0.5 \\
(1.5)\end{array}$ & $\begin{array}{l}2 \cdot 3^{* *} \\
(3 \cdot 3) \\
1 \cdot 7^{* *} \\
(3 \cdot 2) \\
0 \cdot 4 \dagger \\
(1 \cdot 0)\end{array}$ & $\begin{array}{c}1 \cdot 0 \\
(2 \cdot 1) \\
0 \cdot 3 \\
(1 \cdot 2) \\
0 \cdot 3 \\
(1 \cdot 8)\end{array}$ \\
\hline
\end{tabular}

Statistical test: Wilcoxon matched pairs. Significance level set at $p=0.05 .+p<0.05 ; \mathrm{tp}<0.025$; ${ }^{*} \mathrm{p}<0.005 ;{ }^{* *} \mathrm{p}<0.0002$

$\neq \mathrm{DIP}=$ distal interphalangeal; $\mathrm{PIP}=$ proximal interphalangeal; $\mathrm{MCP}=$ metacarpophalangeal.

Table 4 Mean (standard deviation) of the number and area of osteophytes on the medial $(M E D)$ and lateral (LAT) sides of joints of the hand. The significance of the difference in osteophyte number and area between those at the two sides of the joint are indicated in the space between the two columns

\begin{tabular}{|c|c|c|c|c|c|c|c|c|}
\hline \multirow[t]{2}{*}{ foints } & \multicolumn{2}{|l|}{ Index } & \multicolumn{2}{|l|}{ Middle } & \multicolumn{2}{|l|}{ Ring } & \multicolumn{2}{|l|}{ Little } \\
\hline & $L A T$ & $M E D$ & $L A T$ & $M E D$ & $L A T$ & $M E D$ & $L A T$ & $M E D$ \\
\hline $\begin{array}{l}\text { Number } \\
\text { DIP } \\
\text { PIP¥ } \\
\text { MCP }\end{array}$ & $\begin{array}{c}1 \cdot 2^{* *} \\
(1 \cdot 0) \\
0 \cdot 6^{* *} \\
(0 \cdot 9) \\
0 \cdot 4^{*} \\
(0 \cdot 6)\end{array}$ & $\begin{array}{c}2 \cdot 1 \\
(0 \cdot 9) \\
1 \cdot 4 \\
(1 \cdot 2) \\
0 \cdot 8 \\
(1 \cdot 0)\end{array}$ & $\begin{array}{c}1 \cdot 6 \\
(1 \cdot 1) \\
1 \cdot 2 \mathrm{tt} \\
(1 \cdot 2) \\
0 \cdot 5 \mathrm{Ht} \\
(1 \cdot 1)\end{array}$ & $\begin{array}{c}1.6 \\
(0.9) \\
1.7 \\
(1.3) \\
0.8 \\
(0.9)\end{array}$ & $\begin{array}{c}1 \cdot 1 \\
(1 \cdot 0) \\
0.6^{*} \\
(0.9) \\
0.2 \\
(0.6)\end{array}$ & $\begin{array}{c}1 \cdot 2 \\
(0 \cdot 8) \\
1 \cdot 2 \\
(1 \cdot 1) \\
0 \cdot 4 \\
(0 \cdot 7)\end{array}$ & $\begin{array}{c}1.3 \\
(1.3) \\
0.5 * * \\
(0.7) \\
0.3 \\
(0.7)\end{array}$ & $\begin{array}{c}1.2 \\
(0.9) \\
1.1 \\
(0.9) \\
0.4 \\
(0.6)\end{array}$ \\
\hline $\begin{array}{l}\text { Area }\left(\mathrm{mm}^{2}\right) \\
\text { DIP } \\
\text { PIP } \\
\text { MCP }\end{array}$ & $\begin{array}{c}3.5 \dagger \\
(5 \cdot 3) \\
0.8^{* *} \\
(1.9) \\
0.6^{*} \\
(1.4)\end{array}$ & $\begin{array}{c}4 \cdot 3 \\
(5 \cdot 5) \\
2 \cdot 8 \\
(5 \cdot 0) \\
1 \cdot 1 \\
(2 \cdot 1)\end{array}$ & $\begin{array}{c}3.9 \mathrm{tt} \\
(6.3) \\
1.5^{*} \\
(2 \cdot 3) \\
0.9 \mathrm{tt} \\
(2.6)\end{array}$ & $\begin{array}{c}2 \cdot 6 \\
(3 \cdot 5) \\
3 \cdot 2 \\
(4 \cdot 9) \\
1 \cdot 7 \\
(3 \cdot 2)\end{array}$ & $\begin{array}{c}1 \cdot 2 \\
(2 \cdot 0) \\
1 \cdot 0 * * \\
(2 \cdot 6) \\
0 \cdot 3 \mathrm{H} \\
(0 \cdot 9)\end{array}$ & $\begin{array}{c}1 \cdot 1 \\
(1 \cdot 9) \\
2 \cdot 1 \\
(4 \cdot 5) \\
0 \cdot 8 \\
(1 \cdot 7)\end{array}$ & $\begin{array}{c}1 \cdot 7 \\
(2 \cdot 3) \\
0 \cdot 6^{* *} \\
(1 \cdot 7) \\
0 \cdot 4 \\
(1 \cdot 4)\end{array}$ & $\begin{array}{c}1.5 \\
(2.5) \\
1.9 \\
(3.4) \\
0.3 \\
(1.0)\end{array}$ \\
\hline
\end{tabular}

Statistical test: Wilcoxon matched pairs. Significance level set at $p=0.05 .+p<0.05 ; \quad+p<0.025$; ${ }^{*} p<0 \cdot 005 ;{ }^{* *} p<0 \cdot 0002$.

$\neq \mathrm{DIP}=$ distal interphalangeal; $\mathrm{PIP}=$ proximal interphalangeal; $\mathrm{MCP}=$ metacarpophalangeal.

Table 5 Mean (standard deviation) of osteophyte number and area in dominant and non-dominant hands and wrists at the end of the study. The significance of any difference in osteophyte number and area between the start and end of the study is indicated by an asterisk

\begin{tabular}{|c|c|c|c|c|}
\hline \multirow[t]{2}{*}{ Foint affected } & \multicolumn{2}{|c|}{ Number of osteophytes } & \multicolumn{2}{|c|}{ Area of osteophytes ( $\left.\mathrm{mm}^{2}\right)$} \\
\hline & Dominant & Non-dominant & Dominant & Non-dominant \\
\hline $\begin{array}{l}\text { Wrist and hand } \\
\text { Hand only } \\
\text { DIPt } \\
\text { PIPt } \\
\text { MCPY } \\
\text { 1st CMCt } \\
\text { Wrist }\end{array}$ & $\begin{aligned} 31 \cdot 4 & (11 \cdot 7)^{*} \\
27 \cdot 8 & (10 \cdot 9)^{*} \\
12.6 & (4 \cdot 2)+\dagger \\
10 \cdot 8 & (6 \cdot 5)^{*} \\
4 \cdot 4 & (4 \cdot 0) \\
1.5 & (1 \cdot 6) \\
2.1 & (1 \cdot 7)\end{aligned}$ & $\begin{array}{l}29.0(11 \cdot 8)^{*} \\
24.8(11 \cdot 1)^{* *} \\
12.6(4 \cdot 8)^{*} \\
7.9(5.5) \mathrm{Ht} \\
4.4(3.9) \mathrm{Ht} \\
1.8(1.7) \\
2.4(1.9)\end{array}$ & $\begin{array}{c}73 \cdot 2(50 \cdot 7)^{* *} \\
54 \cdot 7(47 \cdot 3)^{* *} \\
25 \cdot 4(27 \cdot 2)^{*} \\
9 \cdot 4(21 \cdot 4)^{*} \\
10 \cdot 0(15 \cdot 1) \mathrm{t} \\
11.9(23 \cdot 9) \\
6.6(11 \cdot 5)\end{array}$ & $\begin{array}{c}67.9(41 \cdot 1)^{*} \\
41 \cdot 7(35 \cdot 0)^{* *} \\
20.2(17 \cdot 8)^{* *} \\
13.7(19 \cdot 5)^{*} \\
7.9(9 \cdot 6)^{* *} \\
18.5(25.9) \\
7.7(14.0)\end{array}$ \\
\hline
\end{tabular}

Test used: Wilcoxon matched pairs. Significance level set at $p=0.05 .+p<0.05 ; \quad+p<0.02$ ${ }^{*} \mathrm{p}<0.005 ;{ }^{* *} \mathrm{p}<0.0002 ;$ †For abbreviations see table 1 . mean osteophyte number and area in the joints of the second and third rays was about twice as large as those in the fourth and fifth rays (table 2). The joints of the third ray had the greatest number and area of osteophytes. Among individual joints, the second DIP joint was the single most affected hand joint (fig 2). Within the joints of the fourth and fifth rays osteophytes occurring at the fifth DIP joint tended to be more numerous and larger.

Comparison between capsular and marginal osteophytes showed that the latter were significantly more prevalent and larger at all of the joints other than the third and fourth MCP joints (table 3). The extent of osteophyte formation on the medial (ulnar) and lateral (radial) sides of the joint showed a more variable pattern. In general, the number and area of osteophytes tended to be greater on the medial side of the joints, and was significantly so at the second DIP joint, at all the PIP and the second and third MCP joints, and in area alone at the fourth MCP joint. The exception was the third DIP joint in which osteophyte area was significantly larger on the lateral (radial) side (table 4). There was no significant difference between the proximal and distal parts of each joint. Osteophyte area, however, tended to be larger on the proximal side but only significantly so $(p<0.025)$ in a few joints of the hand-namely, the third and fourth DIP, fourth PIP, and all MCP joints.

Over the 18 month period of the study the number and area of osteophytes in the whole wrist and hand increased significantly (table 5). The first CMC joint and the wrist separately showed no significant change. Significant increases in number were found in the DIP and PIP joints of dominant and non-dominant hands and the MCP joints of the non-dominant hand. The changes in area were even more significant in all the joint groups (DIP, PIP, and MCP) for both dominant and non-dominant hands. There was no significant difference in the pattern of osteophyte formation between the start and end of the study.

\section{Discussion}

The correspondence between osteophyte formation and the pattern of force distribution is seen here by the greater number and area of osteophytes in the dominant hand, ${ }^{9-11}$ and on the lateral (radial) side of the hand. ${ }^{9} 11$ Our findings showed that the number and area of osteophytes in the second and third phalangeal rays were twice that present in the fourth and fifth rays. This pattern was consistent with the forces associated with the tripod of finger action required in precision grip. ${ }^{19-21}$ Further, the greatest osteophyte formation occurred within the third phalangeal ray and at the second DIP joint, corresponding to the largest forces exerted across these joints during the actions of power and pulp pinch grip respectively. ${ }^{22}$ At the fifth DIP joint osteophyte number and area were greater, though not significantly, than at other joints in the fourth and fifth rays. This difference was probably associated with increased load applied to the fifth terminal phalanx in provid- 
ing support and balance to the hand during precision movements. ${ }^{20}$ The larger number and area of osteophytes at the medial borders of the second DIP, all the PIP, and second, third, and fourth MCP joints was present because these joints tend to show an ulnar deviation related to the muscular contraction within the extensor expansion. ${ }^{22}$ This produces an increased mechanical load at the medial joint margin, resulting in increased osteophyte formation. Apart from the second the remaining DIP joints showed a radial deviation and this was found to be associated with significantly larger osteophytes at the lateral margin of the third DIP joint and a tendency for osteophytes to be larger on that side in the fourth and fifth DIP joints.

In the wrist the greatest osteophyte formation was at the base of the thumb in the nondominant hand, confirming earlier observations. ${ }^{9-11} 23$ In particular, the trapezium had an osteophyte area twice that of the dominant hand located at the site of the capsular and lateral colateral ligament insertions. This, we suggest, is probably due to larger forces produced in these structures in the non-dominant hand during power grip, such as that used in the wringing action. In the dominant hand the intensity of the forces produced in the same region may be less owing to the relatively greater strength of the fingers in grasping objects as in a power grip. ${ }^{22}$

Active bone growth at the joint margins has been noted in osteoarthritis of the hand and knee. ${ }^{411}$ Over the 18 months of this study osteophytes increased significantly in number and particularly in area, indicating that these features are part of an active disease process and quite distinct from those associated with the aging process, which alter in size more slowly. ${ }^{1-4}$ These findings agree with those of Altman $e t$ $a l,{ }^{6}$ who found that osteophytes were the most important feature in identifying and assessing the progression of osteoarthritis in the hands.

Recently, in a study of this same group of patients with osteoarthritis, we found that osteophytes and subchondral sclerosis occur in the hands before the radiographic detection of joint space narrowing. ${ }^{24}$ The indications are that the early response of bone was consequential to the subtle changes in the biochemical composition and stiffness characteristics of articular cartilage; changes that we believe precede the occurrence of cartilage fibrillation followed by loss and narrowing of joint space. ${ }^{24}$ This supports the earlier suggestion that osteophytes are part of the response of bone to increased mechanical load associated with cartilage degeneration. ${ }^{7}{ }^{25}$ Evidence for this was seen here as osteophytes were significantly greater in number and area at the joint margins than at the capsular attachments, and, additionally, there was no real difference between the proximal and distal articular elements of each joint. In addition to the increased load imposed on the subchondral bone, by changes in the articular cartilage, are the effects of forces exerted across the hand and wrist during normal activity, which has led to the particular pattern of osteophyte formation described here. Thus osteophyte formation is not due to abnormal forces in joints ${ }^{5}$ but to existing forces exerting a greater load on the subchondral bone owing to altered mechanical properties of the articular cartilage.

This study was supported by a grant trom Ciba Geigy rnarmaceuticals. The authors would like to thank the members of the international cartilage project (Ciba Geigy) for their support and encouragement and in particular Drs B Levis and M K Jasani. We would also like to thank Mrs B Clark, Mr I Carmichael, and Mrs $\mathbf{H}$ Rees for their assistance.

1 Danielsson L G, Hernborg J. Clinical and roentgenologic study of knee joints with osteophytes. Clin Orthop 1970; 69: 302-12.

2 Jacqueline F, Arlet J, Laporte C. La coxite densifiante a evolution benigne. Rev Rhum Mal Osteoartic 1950; 17: 114-20.

3 Veraguth P C. La tete femorale du veillard; etudes de ses transformations seniles et de leurs rapport avec la coxathrose. transformations seniles et de leurs rapport avec

4 Hernborg J, Nilson B E. The relationship between osteophytes in the knee joint, osteoarthritis and aging. Acta Orihop Scand 1973; 44: 69-74.

5 Moskowitz $\mathbf{R} \mathbb{W}$. Experimental models of osteoarthritis. In: Moskowitz R W, Howell D S, Goldberg V M, Mankin H J, eds. Osteoarthritis, diagnosis and management. Philadelphia: Saunders, 1984: 109-28.

6. Altman R D, Fries J F, Bloch D A, et al. Radiographic assessment of progression in osteoarthritis. Arthritis Rheum 1987; 30: 1214-25.

7 Radin E L, Parker H G, Paul I L. Pattern of degenerative arthritis. Preferental involvement of distal finger joints. Lancet 1971; i: 377-9.

8 Hadler N M, Gillings D B, Imbus H R, et al. Hand structure and function in an industrial setting. Influence of three patterns of stereotyped, repetitive usage. Arthritis Rheum 1978; 21: 210-20.

9 Acheson R M, Chan Y-K, Clementt A R. New Haven survey of joint diseases. XII: Distribution and symptoms of osteoarthrosis in the hands with reference to handedness. osteoarthrosis in the hands with refor

10 Sokoloff $\mathrm{L}$. Loading and motion in relation to aging and degeneration of joints: implications for prevention and treatment of osteoarthritis. In: Helminen $\mathbf{H}$ J, Kivaranta I, Saamanen A-M, Tammi M, Paukkonen $K$, Jurvelin J, eds. foint loading. Biology and health of articular structures. Bristol: Wright, 1987: 412-24.

11 Dickson R A, Morrison J D. The pattern of joint involvement in hands with arthritis at the base of the thumb. Hand 1979 11: 249-55.

12 Buckland-Wright J C. A new high-definition microfocal $x$-ray unit. Br J Radiol 1989; 62: 201-7.

13 Buckland-Wright J C, Bradshaw C R. Clinical applications of high definition microfocal radiography. $B r \mathcal{F}$ Radiol 1989; 62: 208-17.

14 Buckland-Wright J C, Carmichael I, Walker S R. Quantitative microfocal radiography accurately detects joint changes in microfocal radiography accurately detects joint changes
rheumatoid arthritis. Ann Rheum Dis 1986; 45: 379-83.

15 Buckland-Wright J C. X-ray assessment of activity in rheumatoid arthritis. $\mathrm{Br} \mathcal{F}$ Rheumatol 1983; 22: 3-10.

16 Buckland-Wright J C. Advances in the radiological assessment of rheumatoid arthritis. $\mathrm{Br} \mathcal{F}$ Rheumatol 1983; 22 (suppl): 34-43.

17 Buckland-Wright J C. Microfocal radiographic examination of erosions in the wrist and hands of patients with rheumatoid arthritis. Ann Rheum Dis 1984; 43: 160-71.

18 Norusis M J. SPSS/PC+ for the IBM PC/XT/AT. Chicago: SPSS Inc, 1986.

19 Napier J R. The form and function of the carpo-metacarpal joint of the thumb. $\mathcal{F}$ Anat $1955 ; 89: 362-9$.
ions

20 Backhouse K M, Hutchings R T. A colour atlas of surface anatomy clinical and applied. Netherlands: Wolfe Medical, anatomy clinical

21 Tubiana R, Thomine J-M, Mackin E. Examination of hand and upper limb. Philadelphia: Saunders, 1984.

22 Jones A R, Unsworth A, Haslock I. A microcomputer controlled hand assessment system used for clinica measurement. Engineer Med 1985; 14: 191-8.

23 Aune $S$. Osteo-arthritis in the first carpo-metacarpal joint. Acta Chir Scand 1955; 109: 449-56.

24 Buckland-Wright J C, Macfarlane D G, Lynch J A, Clark B. Quantitative microfocal radiographic assessment of pro-
gression in osteoarthritis of the hand. Arthritis Rheum 1990; 33: 57-65.

25 Moskowitz $R$ W, Goldberg V M. Osteophyte evolution: studies in an experimental partial menisectomy model. f Rhewoutol 1987; 14 (suppl 14): 116-9. 